\section{Reactions to Tetanus Toxoid}

When tetanus toxoid came into routine use in Europe and North America in 1938, little significance was attached to previous reports of local reactions ${ }^{12}$ and urticaria $^{3}$ following its administration. They had been ascribed to delayed-type hypersensitivity to antigenic proteins present in the culture medium. ${ }^{1}$ But in 1940, after further reports of urticaria ${ }^{4}$ and a $1 \%$ reaction rate, ${ }^{5}$ they were attributed to Witte peptone in the culture medium, the use of silk filters, and to delayed-type hypersensitivity. ${ }^{4}$

The development of a culture medium initially free of antigenic components ${ }^{6}$ was followed by a period of about 15 years without further reports of adverse reactions, but after J. E. Sweeney's report of three cases of severe local reactions in $1959^{7}$ it was realized that there was a low but increasing incidence of reactions, affecting in particular persons who had received several previous inoculations. ${ }^{8}$

Reactions to tetanus toxoid rarely occur in children and their incidence in adults increases with age. ${ }^{910}$ Women are more susceptible than men, ${ }^{10-12}$ but they also produce higher antitoxin responses. ${ }^{13}$ Plain toxoid is less reactogenic than the aluminium-adsorbed preparation, ${ }^{9}{ }^{1114-16}$ but it is also less antigenic and provides a shorter period of immunity. ${ }^{17}$ Intramuscular injection has been found to result in fewer reactions than subcutaneous, ${ }^{12}$ but the contrary has also been reported. ${ }^{18}$ There is no doubt, however, that inoculation into the gluteal region gives rise to the least number of reactions. ${ }^{18}$ The incidence of reactions increases according to the number of previously administered doses, ${ }^{9121920}$ though reactions can occur after the first dose. ${ }^{111618} \mathrm{~W}$. G. White and his associates, ${ }^{10}$ in a study on 6,740 industrial workers, reported reaction rates of $0.9,2 \cdot 7,7 \cdot 4$, and $1.6 \%$ after the first, second, third, and booster doses respectively. The incidence rate of reactions in adults is usually between 1 and $2 \%{ }^{511} 1221$

Urticaria with or without angioneurotic oedema is the commonest general reaction, ${ }^{342022} 23$ but frank serum sickness ${ }^{24}$ and peripheral neuropathy ${ }^{25}$ have also been described. Local reactions consist of excessive pain, redness, and swelling round the site of injection persisting for up to three or four days. ${ }^{10-12} 14$ The general and local reactions may develop after an interval varying from a few minutes ${ }^{1622}$ to several days. ${ }^{3} 1126$

Though reactions have been regarded as symptoms of delayed-type hypersensitivity to antigenic impurities, ${ }^{18}$ they are not eliminated by further purification of the toxoid, ${ }^{1011}$ though they are reduced by halving the amount of toxoid in a dose. ${ }^{10}$ The antibacterial preservative thiomersal, which is added to the toxoid, can produce delayed-type hypersensitivity reactions ${ }^{27}$ but apparently is not responsible for tetanus toxoid reactions. ${ }^{10}$ The adjuvant aluminium hydroxide can also produce a persistent granuloma at the site of injection, ${ }^{28}$ but this complication is rare.

During recent years all general reactions and most local reactions have been attributed to precipitating antigenantibody complexes in antigen excess, tetanus toxoid itself being the antigen. ${ }^{11}$ Recently M. A. Facktor and his co- workers $^{29}$ reported a high incidence of cutaneous hypersensitivity reactions to tetanus toxoid in 70 persons ranging from 6 months to 49 years of age. All had been previously immunized with at least three doses of toxoid but few had experienced any untoward effects. Nevertheless $63 \%$ had immediate allergic skin reaction to a $0.02 \mathrm{ml}$ intradermal test dose of toxoid, 32\% had an Arthus-type reaction, and 74\% had a delayed-type hypersensitivity reaction. The toxoid was not given to a comparable group of unvaccinated persons, and there was no evidence that those given a positive skin test would suffer any clinical effects if given an immunizing dose of toxoid. However, the authors concluded that the results of the skin test indicate that tetanus toxoid possesses the potential, if overused, of precipitating hypersensitivity reactions. T. C. Peebles and colleagues ${ }^{30}$ had previously shown that persons who had had four or more spaced injections have protective levels of antitoxin which will persist for at least 12 years and are particularly prone to clinical reactions if immunized further.

Reactions to tetanus toxoid do not endanger life, do not leave any sequelae, and do not occur in more than about $1 \%$ of adults, mainly the overimmunized. They are recorded only in countries where tetanus mortality has always been low but overimmunization is common. In warmer countries, where tetanus has always been, and still is, a common cause of death, the problem is not one of transient reactions in the overimmunized but of providing the population with the minimum number of tetanus toxoid doses required to protect against fatal infection.

${ }^{1}$ Bergey, D. H., and Etris, S., American fournal of Public Health and the Nation's Health, 1934, 24, 582

2 Jones, F. G., and Moss, J. M., fournal of Immunology, 1936, 30, 115.

3 Hall, W. W., Military Surgeon, 1937, 80, 104.

4 Hall, W. W., Military Surgeon, 1937, 80, 104. American Medical Association, 1940, 114, 1854.

5 Whittingham, H. E., British Medical fournal, 1940, 1, 292

6 Mueller, J. H., and Miller, P. A., Fournal of Immunology, 1943, 47, 15. Sweeney, J. E., Fournal of the American Medical Association, 1959, 169, 1398

${ }^{8}$ Edsall, G., Fournal of the American Medical Association, 1959, 171, 417.

Levine, L., Ipsen, J., and McComb, J. A., American fournal of Hygiene, $1961,73,20$.

10 White, W. G., et al., fournal of Hygiene, 1973, 71, 283.

${ }^{11}$ Griffith, A. H., in Principles on Tetanus. Proceedings of the 2nd International Conference on Tetanus, ed. L. Eckmann, p. 299. Bern, Huber, 1967.

Relinal Conference on Tetanus, ed. L. Eckmann, p. 299. Bern, Huber,

13 Parish, H. J., and Maclean, I. H., Proceedings of the Royal Society of Medicine, 1941, 34, 247.

14 Eisen, A. H., Cohen, J. J., and Rose, B., New England fournal of Medicine, 1963, 269, 1408.

${ }^{15}$ Holden, J. M., and Strang, D. U., New Zealand Medical fournal, 1965, 64, 574

${ }^{16}$ Kittler, F. J., Smith, P., Hefley, B. F., and Cazort, A. G., Scottish Medical Journal, 1966, 59, 149.

7 White, W. G., et al., Lancet, 1969, 2, 95

8 David, D., and Zehntner, B., Schweizerische medizinische Wochenschrift, $1971,101,1055$.

${ }^{19}$ Kuhns, W. J., Fournal of Immunology, 1962, 89, 652.

20 Edsall, G., Eiliot, M. W., Peebles, T. C., Levine, J., and Eldred, M. C., Fournal of the American Medical Association, 1967, 202, 17.

${ }^{21}$ Sisk, C. W., and Lewis, C. E., Archives of Environmental Health, 1965, $11,34$.

${ }^{22}$ Brindle, M. J., and Twyman, D. G., British Medical Fournal, 1962, 1, 1116.

23 Fardon, D. F., Fournal of the American Medical Association, 1967, 199, 125 ,

${ }^{24}$ Daschbach, R. J., Fournal of the American Medical Association, 1972, 220,

1619.
${ }^{25}$ Blumstein, G. I., and Kreithen, H., fournal of the American Medical Association, 1966, 198, 1031.

Association, 1966, 198, 1031.
26 Schneider, C. H., Medical fournal of Australia, 1964, 2, 303.

27 Reisman, R. E., fournal of Allergy, 1969, 43, 245.

28 Savage, J., Proceedings of the Royal Society of Medicine, 1973, 66, 984

Facktor, M. A., Bernstein, R. A., and Fireman, P., Fournal of Allergy and Clinical Immunology, 1973, 52, 1.

${ }^{3}$ Peebles, T. C., Levine, L., Eldred, M. C., and Edsall, G., New England fournal of Medicine, 1969, 280, 575. 